\title{
Prevalence of Strongyloides robustus in Tree Squirrels (Sciuridae) in South-Central Pennsylvania and Potential Impacts for the Endangered Northern Flying Squirrel, Glaucomys sabrinus
}

\author{
Jessica L. Espenshade ${ }^{\mathrm{a}}$ and Richard L. Stewart ${ }^{\mathrm{a}}$
}

\begin{abstract}
The northern flying squirrel is an endangered species in the state of Pennsylvania. Many hypotheses potentially explain the diminished population, with the most supported being parasitic infection. While infection with the parasite Strongyloides robustus presents with benign pathology in some squirrel species, like the southern flying squirrel (Glaucomys volans), the eastern gray squirrel (Sciurus carolinensis) and the red squirrel (Tamiasciurus hudsonicus), S. robustus infection can result in high mortality in the northern flying squirrel (Glaucomys sabrinus). Past research has focused primarily on the transmission between northern and southern flying squirrels; however this project aims to better evaluate the risk to northern flying squirrels in light of the parasite mediated competition hypothesis by surveying the prevalence of $S$. robustus within other sympatric reservoirs currently found throughout Pennsylvania. In order to survey parasite presence, fecal samples from eastern gray, red, and southern flying squirrels were obtained from nest boxes, road kills and hunting. Strongyloides robustus was present in $30 \%$ of the 10 southern flying squirrel samples. The prevalence of $S$. robustus was $77.3 \%$ in the 22 road-killed and hunter-killed eastern gray squirrels. The single hunter-killed red squirrel examined in this study demonstrated S. robustus infestation. The results in this study area supported the hypothesis of parasite mediated competition on a broader scale because of the high infection rate in potential sympatric reservoirs. Surveillance of $S$. robustus in localized populations should occur prior to initiating recovery plans for the northern flying squirrel and management of this parasite in reservoir populations should be considered.
\end{abstract}

Keywords: Parasite, Squirrels, Endangered

\section{Introduction}

Glaucomys sabrinus, the northern flying squirrel, has a population size that is considered secure nationally (Butchkoski and Turner 2010). However in parts of its range, it is either a candidate for endangered listing or is already considered endangered (USFWS 2012). For example, the northern flying squirrel is currently on the state endangered species list in Pennsylvania. A number of potential factors may have led to this status; including climate change, habitat destruction, insect pests, Strongyloides robustus infections, and urban development (Krichbaum et al. 2010, Title 58, Mahan et al. 1999). Northern flying squirrels have unique habitat preferences and prefer $>95$ year old mixed coniferous forests adjacent to a permanent water source. This habitat usually also contains a significant number of overstory trees (including spruce, northern hardwood and other mixedconiferous-hardwood forest types), saplings and rock cover (Mahan et al. 2010 and Smith 2007). However, northern flying squirrels have been flexible in their habitat requirements under pressure (Weigl 2007).

Historically, the range of the northern flying squirrel covered the majority of Pennsylvania and south into parts of Tennessee (Burt 1957). However, by 1995 the documented range had diminished greatly. Habitat is being destroyed, resulting in smaller, fragmented populations of the northern flying squirrel (Mahan et al. 1999). Populations are no longer present in south-central Pennsylvania and the southern U.S. populations are greatly isolated on specific mountaintops (Kurta 1995 and Sparks 2005).
When populations of the northern flying squirrel become isolated, a number of other, potentially more dangerous, factors arise. Small populations exhibit lower genetic diversity due to increased rates of inbreeding, and inbreeding has been linked to increased potential for parasitic infection (Sparks 2005). Inbreeding causes a lack of genetic fitness and consequently a lack of immune response (Stevens et al. 1997; Allendorf and Leary 1986). Therefore, it is possible that reductions in genetic diversity due to inbreeding may be associated with an increased level of parasitism by Strongyloides robustus.

Strongyloides robustus is one of the most common helminths in squirrels. Members of the genus Strongyloides are roundworms that can cause skin pathology, pulmonary and/or intestinal distress in host species (Roberts et al. 2009). Only two out of the 35 different Strongyloides species, $S$. robustus and $S$. papillosus, are known to parasitize squirrels. For most squirrel species, there are no known deleterious effects from $S$. robustus. That being said, these squirrels can serve as reservoirs for infection. Historically, S. papillosus was recorded from eastern gray squirrels in Tennessee by Reiber and Byrd (1942) but has not since been documented in the northern United States or Canadian provinces.

Sparks (2005) suggested the hypothesis of parasite mediated competition for sympatric flying squirrel species. The parasite mediated competition hypothesis predicts that when multiple species are hosts to the same parasite, one host will become more tolerant of the parasite while the others do not acquire the same resistance (Price et al. 1988). Krichbaum 
et al. (2010) tested this prediction and collected data that partially supported the parasite mediated hypothesis in sympatric populations of northern and southern flying squirrels. Although no ill effects from S. robustus infection in southern flying squirrel have been identified; when $S$. robustus infects northern flying squirrels, it seems to suppress the squirrel's ability to put on winter weight or even maintain their current weight. The result of this infection can be fatal (Wetzel and Weigl 1994).

Focusing research on the transmission between the northern and southern flying squirrels is limited in its application. The vulnerable northern flying squirrel is in contact with other squirrel species such as the red squirrel, fox squirrel and the eastern gray squirrel throughout its range. Little evidence has been published examining the abundance of this parasite in these other common sympatric squirrel species. The exclusion of potentially important information relating to sources for parasite transmission could be a very important reason explaining decline in the northern flying squirrel. To better understand the abundance and prevalence of $S$. robustus in potential reservoir populations, we conducted a survey for this parasite in squirrel species located in south-central Pennsylvania using a simplified fecal-float method of detection. Our goal was to add information to the previous records of $S$. robustus parasitism in order to evaluate the parasite mediated competition hypothesis on a broader scale.

Pennsylvania has seven squirrel species (ASM 2012) and all but the northern flying squirrels have established populations near Shippensburg (Stewart et al. 2008). Within their distributions, many of these squirrel territories overlap and therefore a high rate of competition between the squirrels may exist. Nest sharing could provide the necessary habitat overlap to inoculate the nest with fecal material and therefore introduce parasites into the habitat. If there is a high prevalence of $S$. robustus in any squirrel species, it could potentially reduce or eliminate the northern flying squirrel populations when the parasite is transmitted between species.

In this survey, three species of squirrels were evaluated for the presence of $S$. robustus. These species include: the eastern gray squirrel (Sciurus carolinensis), the red squirrel (Tamiasciurus hudsonicus), and the southern flying squirrel (Glaucomys volans). No information is available concerning the prevalence of $S$. robustus throughout most of Pennsylvania including Franklin and Cumberland counties. These results will aid in our understanding of the parasite mediated competition hypothesis providing detail to the relationship of $S$. robustus and the declining populations of the northern flying squirrel. We hypothesized that $S$. robustus will be prevalent in all three squirrel species being tested which may have resulted in the absence of northern flying squirrels in the study area.

\section{Materials and Methods}

Fecal samples were collected from eastern gray, red and southern flying squirrels. The flying squirrel samples were obtained from 40 previously placed nest boxes on land adjacent to Pennsylvania State Game Lands 169 near Newville, PA. The eastern gray and red squirrel samples were collected from road kills and hunter-harvested squirrels. The locations where these squirrels were found include Letterkenny Army Depot (Franklin County, PA), and the area surrounding Newburg, PA and Shippensburg, PA (both Cumberland County, PA).

Dried fecal samples were taken from the flying squirrel nest boxes. The eastern gray and red squirrel fecal samples were removed directly from the squirrel's colon. To concentrate eggs within the feces, the samples were placed in test tubes and mixed with a modified Sheather's sugar flotation solution (Dryden et al. 2005). Sheather's sugar solution has been successfully used in other experiments to identify helminthes in squirrels including: Eimeria (Fuller and Duszynski 1997), Strongyloides robustus and Citellinemia bifurcatum (Pedder et al. 2009).

Sheather's solution was prepared with a specific gravity of 1.27 and a wooden applicator stick was used to mix in the fecal sample. Additional Sheather's solution was added until a meniscus formed on top of the test tube at which point a microscope slide was placed on top of the meniscus. After 5 minutes the slide was removed and inverted before a coverslip was placed on the area with Sheather's solution to determine parasite egg presence. Slides were observed under 40X magnification using a student Leica CM E microscope. The parasites were identified by being the only strongyloid that infects squirrels and by egg dimensions of $45-72 \mu \mathrm{m}$ by $27-$ $42 \mu \mathrm{m}$ (Chandler 1942; Sloss et al. 1994; Bartlett 1995).

\section{Results}

Samples from thirty three squirrels were collected including; 10 southern flying squirrels, 22 eastern gray squirrels and 1 red squirrel. Live flying squirrels were not documented in the nest boxes; however, their presence was noted by gray underbelly pelage (Krichbaum et al. 2010) and one occurrence of three deceased infant flying squirrels. Ten of the 40 nest boxes contained southern flying squirrel evidence including fur. Fecal pellets deposited within the nest were collected.

Eggs of $S$. robustus were identified in 21 out of the 33 samples. Three of the 10 southern flying squirrel (30\%) samples were positive. Seventeen of the 22 eastern gray squirrel $(77.3 \%)$ road-killed and hunter-killed samples were positive. The single red squirrel examined in this study exhibited $S$. robustus infection and was collected through hunter-harvest (Table 1.) 
Table 1: Number of individuals sampled and prevalence of Strongyloides robustus infestation identified from eggs from species in Pennsylvania and New York.

\begin{tabular}{|c|c|c|c|c|c|c|c|c|c|c|}
\hline \multirow[b]{2}{*}{$\begin{array}{l}\text { Squirrel } \\
\text { Species }\end{array}$} & \multicolumn{2}{|c|}{$\begin{array}{c}\text { Essex County (NY) } \\
\text { Krichbaum et al. } 2010\end{array}$} & \multicolumn{2}{|c|}{$\begin{array}{c}\text { Carbon, Pike, Warren } \\
\text { Counties (PA) } \\
\text { Krichbaum et al. } 2010\end{array}$} & \multicolumn{2}{|c|}{$\begin{array}{c}\text { Northeastern } \\
\text { Pennsylvania } \\
\text { from Pedder et al. } \\
\mathbf{2 0 0 9} \\
\end{array}$} & \multicolumn{2}{|c|}{$\begin{array}{c}\text { Nolo, PA (Indiana } \\
\text { County) from Patrick } \\
1991\end{array}$} & \multicolumn{2}{|c|}{$\begin{array}{c}\text { South-central } \\
\text { Pennsylvania } \\
\text { Current Study } \\
2012 \\
\end{array}$} \\
\hline & $\begin{array}{l}\text { Number } \\
\text { sampled } \\
(\mathrm{N})\end{array}$ & $\begin{array}{l}\text { Prevalence } \\
(\%)\end{array}$ & $\begin{array}{l}\text { Number } \\
\text { sampled } \\
(\mathrm{N})\end{array}$ & $\begin{array}{l}\text { Prevalence } \\
(\%)\end{array}$ & $\begin{array}{l}\text { Number } \\
\text { sampled } \\
(\mathrm{N})\end{array}$ & $\begin{array}{l}\text { Prevalence } \\
(\%)\end{array}$ & $\begin{array}{l}\text { Number } \\
\text { sampled } \\
(\mathrm{N})\end{array}$ & $\begin{array}{l}\text { Prevalence } \\
(\%)\end{array}$ & $\begin{array}{l}\text { Number } \\
\text { sampled } \\
\text { (N) }\end{array}$ & $\begin{array}{l}\text { Prevalence } \\
(\%)\end{array}$ \\
\hline $\begin{array}{l}\text { Glaucomys } \\
\text { volans }\end{array}$ & $*$ & --- & 20 & 45 & 9 & 11.1 & 10 & 100 & 10 & 30 \\
\hline $\begin{array}{l}\text { Glaucomys } \\
\text { sabrinus }\end{array}$ & 7 & 0 & 4 & 75 & 2 & 50 & --- & --- & --- & --- \\
\hline $\begin{array}{l}\text { Sciurus } \\
\text { carolinensis }\end{array}$ & --- & --- & --- & --- & 6 & 0 & --- & --- & 22 & 77.3 \\
\hline $\begin{array}{l}\text { Tamiasciurus } \\
\text { hudsonicus }\end{array}$ & --- & --- & --- & --- & --- & --- & --- & --- & 1 & 100 \\
\hline $\begin{array}{l}\text { Tamias } \\
\text { striatus }\end{array}$ & --- & --- & --- & --- & 3 & 0 & --- & --- & & \\
\hline Total & 7 & & 24 & & 20 & & 10 & & 33 & \\
\hline
\end{tabular}

* No Glaucomys volans were present.

\section{Discussion}

We compared our results in south-central Pennsylvania to previous experiments in other parts of Pennsylvania and New York where the northern flying squirrel was historically (Burt 1957) or is currently found (Table 1) to better illustrate how parasite distribution may affect northern flying squirrels. In Essex county New York, where there is a healthy population of northern flying squirrels and no southern flying squirrels, no Strongyloides robustus infection was observed in the 7 specimens tested (Krichbaum et al. 2010). However, in the Pennsylvania counties of Carbon, Pike and Warren where the southern and northern flying squirrels occur sympatrically, $45 \%(n=20)$ of southern flying squirrels and $75 \%(n=4)$ of northern flying squirrels were infected with $S$. robustus (Krichbaum et al. 2010). Additionally another unidentified location in northeastern Pennsylvania showed similar results with an unhealthy population of northern flying squirrels occurring sympatrically with an infected population of southern flying squirrels (Pedder et al. 2009).

The only other information detailing the infection of squirrels by $S$. robustus in the northeastern historical range of the northern flying squirrel in Pennsylvania was Patrick (1991), who observed a 100\% $(n=10)$ infection rate in southern flying squirrels from Indiana County Pennsylvania where no northern flying squirrels were reported. Both Patrick (1991) and Krichbaum et al. (2010) failed to assess the reservoir potential of other sympatric squirrel species and although Krichbaum et al. (2010) demonstrated results that were consistent with the predictions of the parasite mediated competition hypothesis they did not survey other squirrel species that were present in the area. The lack of potential reservoir inclusion leaves out a key component toward our understanding of the parasite mediated competition hypothesis because it omits a consistent risk factor of transmission. Pedder et al. (2009) surveyed eastern gray squirrels and eastern chipmunks (Tamias striatus) in an attempt to assess risk without detecting infection, however, their sample size (6 gray squirrels) was limited and included the eastern chipmunk, which is not a known reservoir (Anderson, 2000). Our survey hypothesized that a high prevalence of $S$. robustus infection would be observed in south-central Pennsylvania where northern flying squirrels are extirpated. These data support the parasite mediated competition hypothesis and lend increased explanation toward the that explanation for northern flying squirrel decline by demonstrating that the infection rate of other squirrel species can be high in reservoir sympatric squirrels, i.e. gray squirrels $(77 \%, \mathrm{n}=22)$ in this study. As Weigl (2007) notes, there has been concern for the northern flying squirrel over much of its range in North America and therefore many studies have searched for the "magic" factor that might explain its biology and ensure its survival. Unfortunately, there may not be a "magic" factor as the parasite mediated competition hypothesis may be as important as habitat fragmentation or loss of suitable habitat.

While the data contained within this report are a significant contribution towards evaluating the parasite mediated competition hypothesis, the numbers are small, including the evaluation of only one red squirrel. Additional data needs to be contributed so that a more complete picture can be obtained that details the prevalence and distribution throughout the northeastern range of the northern flying squirrel. To further develop the pattern of parasitic infections in Pennsylvania and surrounding areas, the authors recommend that Sheather's solution (Dryden et al. 2005) should be used as the standard floatation method to evaluate the presence of $S$. robustus. Other isolation techniques require direct observation of intestinal presence after the death of the specimen (Bartlett 1995, Patrick et al. 1991) or the use of a modified formalin-ethyl acetate sedimentation technique (Pauli et al. 2004) that is more difficult to make and use. Sheather's sugar flotation solution was a vital part of this experiment and that of Pedder et al. (2009). Sheather's sugar solution was used because it has a quick preparation time, uses a simple design and inexpensive ingredients, as well as 
possessing the highest specific gravity (1.27) of other common floatation solutions (Dryden et al. 2005). These attributes increase the opportunity for easy use for other undergraduate or graduate students and should result in more data generated detailing the geographical range of the parasite. Most importantly, the design followed here is a noninvasive survey method, relying on deposited fecal matter. Survivorship is the key when working with any endangered species.

Since $S$. robustus has deleterious effects for the northern flying squirrel, future research should focus on both increasing the resistance to the parasite, as well as decreasing the presence of the parasite in sympatric squirrel species. To increase resistance, conservationists should increase gene flow by decreasing fragmentation. Consequently, conservation efforts should focus on developing corridors between the forest fragments to increase out-breeding and this may result in an increase resistance to the deleterious effects of $S$. robustus. However, even if suitable habitats exist in south-central Pennsylvania or other areas within the northern flying squirrel's historical range, it is unlikely that a reintroduction effort would be successful without treatment for the parasite in the squirrel community. Baiting with ivermectin medicated bait, such as peanut butter or corn, may be considered to eliminate the risk of parasitic infection, similar to the way it has been successfully used to reduce tick parasitism (Pound et al. 1996).

Unidentified parasite reservoirs for $S$. robustus have been historically overlooked by researchers trying to understand the decline of the northern flying squirrel and this lack of data does not permit researchers to effectively evaluate the parasite mediated competition hypothesis. Our data demonstrates that $S$. robustus can be locally abundant in reservoir sympatric squirrels, which will assist in later conservation efforts. Understanding the relationship between sympatric squirrel species and their reservoir roles for $S$. robustus where the last remnants of the endangered northern flying squirrel exist will aid in the development of an effective species recovery plan.

\section{Acknowledgement}

We would like to thank several unnamed hunters, personnel at Letterkenny Army Depot, Jen Wysocki for collecting roadkilled squirrels, Brett Loski for placing the flying squirrel boxes and Dr. Tim Maret for allowing access to the boxes located on his property and Dr. Nathan Thomas for squirrels obtained with the Pennsylvania Game Commission permit SAL00580. Funding for this project was provided by the Shippensburg Undergraduate Research Advisory Committee UGR2011/12-18.

\section{Literature Cited}

Allendorf, F.W., and R.F. Leary. 1986. Heterozygosity and fitness in natural populations of animals. Pp. 57-76 in M. E. Soule, ed. Conservation biology: the science of scarcity and diversity. Sinauer, Sunderland, MA.

American Society of Mammalogists (ASM) 2012. Mammals of Pennsylvania. Retrieved June 5, 2012 from http://www.mammalogy.org/mammals-pennsylvania
Anderson, R.C. 2000. Nematode Parasites of Vertebrates: Their Development and Transmission. Second edition. Guelph, Ontario: CABI Publishing.

Bartlett, C.M. 1995. Morphology, homogonic development, and lack of a free-living generation in Strongyloides robustus (Nematoda, Rhabditoidea), a parasite of North American sciurids. Folia Parasitologica 42:102-114.

Burt, W.H. 1957. Mammals of the Great Lakes Region. First edition. Michigan: The University of Michigan Press.

Butchkoski, E. and G. Turner. 2010. Northern flying squirrel, Glaucomys sabrinus macrotis. Retrieved September 25, 2012, from http://www.google.com/url?sa=t\&rct=i\&q=\&esrc=s\&fr $\mathrm{m}=1 \&$ source $=$ web $\& \mathrm{~cd}=2 \&$ sqi $=2 \& v e d=0 C C U Q F j A B \& u$ $\mathrm{rl}=\mathrm{http} \% 3 \mathrm{~A} \% 2 \mathrm{~F} \% 2 \mathrm{Fwww} . p 0 r t a l . s t a t e . p a . u s \% 2 \mathrm{Fportal} \%$ 2Fserver.pt $\% 2$ Fdocument $\% 2$ F775666\%2Fnorthern_flyin g_squirrel_pdf\&ei=0mRjUJetFM6x0QHzooDIBQ\&usg =AFQjCNG56asoMCJJDvij66Ibf2oA4eLXvw\&sig2=x1 ID8kxwScpu5Tx8k4oJWw\&cad=rja

Chandler, A.C. 1942. Helminths of tree squirrels in southeast Texas. Journal of Parasitology 28(2): 135-140.

Dryden, M.W., P.A. Payne, R. Ridley, and V. Smith. 2005. Comparison of common fecal flotation techniques for the recovery of parasite eggs and oocysts. Veterinary Therapeutics 6(1):15-28.

Fuller,C.A. and D.W. Duszynski. 1997. Eimera (Protozoa:Eimeriidae) from North American sciurids, Glaucomys sabrinus and Tamias townsendii: with a description of a new species. Faculty Publications from the Harold W. Manter Laboratory of Parasitology. 168.

Krichbaum, K., C.G. Mahan, M.A. Steele, G. Turner, and P.J. Hudson. 2010.The potential role of Strongyloides robustus on parasite-mediated competition between two species of flying squirrels (Glaucomys). Journal of Wildlife Disease 46(1): 229-235.

Kurta, A. 1995. Mammals of the Great Lakes Region. Revised. Michigan: The University of Michigan Press.

Mahan, C.G, J.A. Bishop, M.A. Steele, G. Turner, and W.L. Myers. 2010. Habitat characteristics and revised gap landscape analysis for the northern flying squirrel (Glaucomys sabrinus), a state endangered species in Pennsylvania. American Midland Naturalist 164: 283295.

Mahan, C.G., M.A. Steele, M.J. Patrick, and G.L. Kirkland Jr. 1999. The status of the northern flying squirrel (Glaucomys sabrinus) in Pennsylvania. Journal of the Pennsylvania Academy of Science 73(1): 15-21.

Pauli, J.N., S.A. Dubay, E.M. Anderson, and S.J. Taft. 2004. Strongyloides robustus and the northern sympatric populations of northern (Glaucomys sabrinus) and southern (G. volans) flying squirrels. Journal of Wildlife Diseases 40(3): 579-582.

Patrick, M.J. 1991. Distribution of enteric helminths in Glaucomys volans L. (Sciurdiae): A test for competition. Ecology 72(2): 755-758.

Pedder, S., C.G. Mahan, and A. VanKuren. 2009. Prevalence of parasites including Strongyloides robustus and Citellinemia bifurcatum in the endangered northern flying squirrel and other members of the squirrel family. [Abstract] In: Proceedings of The Pennsylvania Chapter of the Wildlife Society pg. 28. Retrieved April 28, 2012 from 
http://joomla.wildlife.org/PA/images/2009\%20conf\%20p rogram-\%20final.doc

Pound, J.M., J.A. Miller, J.E. George, D.D. Oehler, and D.E. Harmel. 1996. Systemic Treatment of White-tailed Deer with Ivermectin-Medicated Bait To Control Free-Living Populations of Lone Star Ticks (Acari: Ixodidae). Journal of Medical Entomology 33(3): 385-394.

Price, P.W., M. Westoby, and B. Rice. 1988. ParasiteMediated Competition: Some Predictions and Tests. The American Naturalist 131(4): 544-555.

Reiber, R.J., and E.E. Byrd. 1942. Some nematodes from mammals of Reelfoot Lake in Tennessee. Jour. Tenn. Acad. Sci. 17: 78-89.

Roberts, L.S. and J. Janovy Jr. 2009. Gerald D. Schmidt and Larry S. Roberts's Foundations of Parasitology $\left(8^{\text {th }}\right.$ ed.). (pp.414-417). McGraw Hill, Boston, MA.

Sloss, M.W., R.L. Kemp and A.M. Zajac. 1994. Veterinary Clinical Parasitology. Blackwell Publishing. Ames, IA, 4-96.

Smith, W.P. 2007. Ecology of Glaucomys sabrinus: habitat, demography, and community relations. Journal of Mammalogy 88(4): 862-881.

Sparks, J.L. Jr. 2005. Genetic variability, pathogen susceptibility, subspecies identity, and conservation of the endangered northern flying squirrel (Glaucomys sabrinus) in Virginia. Master Thesis, Virginia Commonwealth University, Richmond, Virginia,73pp.

Stevens, L., G. Yan, and L.A. Pray. 1997. Consequences of Inbreeding on Invertebrate Host Susceptibility to Parasitic Infection. Evolution 51(6):2032-2039.

Stewart, R.L. Jr., P.R. Delis, and C.M. Kindlin. 2008. An inventory of the small mammals of Letterkenny Army Depot, Franklin county Pennsylvania. Journal of the Pennsylvania Academy of Sciences 81(2):59-65.

Title 58, Pennsylvania Code, Section 133.41.

U.S. Fish and Wildlife Service, Virginia Field Office (USFWS). 2012. Federally Endangered, Threatened, Proposed, and Candidate Species in Virginia. Retrieved September 25, 2012, from http://www.fws.gov/northeast/virginiafield/pdf/endspecie s/state_list/VaSpeciesList.pdf

Weigl, P.D. 2007. The northern flying squirrel (Glaucomys sabrinus): A conservation challenge. Journal of Mammalogy 88(4):897-907.

Wetzel, E.J. and P.D. Weigl. 1994. Ecological implications for flying squirrels (Glaucomys spp.) of effects of temperature on the in vitro development and behavior of Strongyloides robustus. American Midland Naturalist 131(1): 43-54. 